functional imparment in toluene abusers. Acta Neurol Scand 1983;67: 319-29.

8 Lolin Y. Chronic neurological toxicity from volatile substances of abuse. Hum Toxicol (in press).

9 Chadwick OFD, Anderson HR. Neuropsychological consequences of volatile substance abuse: a review. Hum Toxicol (in press).

10 Plant MA, Peck DF, Samuel E. Alcohol, drugs and school-leavers. London: Tavistock, 1985

11 Johnson LD, O'Malley PM, Bachman JG. Drugs and American high school students: 1975-1983. Rockville, Maryland: National Institute on Drug students: $1975-1983$. Rockville, Maryland: National Institute on Drug

12 Kandel D, Single E, Kessler RC. The epidemiology of drug use among New York State high school students: distribution, trends and changes in rates of use. Am F Public Health 1976;66:43-53.

13 Wechsler D. Wechsler intelligence scale for children-revised. New York: Psychological Corporation, 1974

14 Bate SM. Reading test $E H-3$. Windsor, Berkshire: National Foundation for Educational Research, 1970.

15 Wechsler D. A standardised memory scale for clinical use. $f$ Psychol 1945;19:87-95

16 Elliot C, Murray DJ, Pearson LS. The British ability scales. Windsor, Berkshire: National Foundation for Educational Research, 1983.

17 Acker W, Acker C. The Bexley-Maudsley automated psychological screening test. Windsor, Berkshire: National Foundation for Educational test. Windsor, Berch-Nelson, 1982.

18 Armitage SG. An analysis of certain psychological tests used for the evaluation of brain injury. Psychological Monographs 1946;60:1-48. (No 277.)

19 Annett M. The growth of manual preference and speed. Br $\mathcal{F}$ Psychol Annett M. The g
1970;61:545-58.
20 Bloom S, Till S, Sönksen P, Smith S. Use of a biothesiometer to measure individual vibration thresholds in 519 non-diabetic subjects. Br Med $\mathcal{J}$ 1984;288:1793-5.

21 Anonymous. London reading test: teacher's manual. Windsor, Berkshire: Inner London Education Authority and National Foundation for Educational Research-Nelson, 1980 (table 5)

22 Knave B, Olson BA, Elofsson A, et al. Long-term exposure to jet fuel: cross-sectional epidemiologic investigation on occupationally exposed industrial workers with special reference to the nervous system. Scand $\mathcal{F}$ Work Environ Health 1978;4:19-45.

23 Wechsler D. The measurement and appraisal of adult intelligence. 4th ed. Baltimore: Williams and Wilkins, 1958.

24 Douglas VI. Attentional and cognitive problems. In: Rutter M, ed Developmental neuropsychiatry. New York: Guilford, 1983:280-329.

25 Lishman AW. Organic psychiatry. 2nd ed. Oxford: Blackwell, 1987.

26 Tarter RE. Psychological deficits in chronic alcoholics: a review. Int $\mathcal{F}$ Addic 1975;10:327-68.

27 Ron MA. Brain damage in chronic alcoholism: a neuropathological, neuroradiological and psychological review. Psychol Med 1977;7:103-12.

28 Rutter M, Graham P, Yule W. A neuropsychiatric study in childhood. London: Spastics International Medical Publications-Heinemann Medical Books, 1970. (Clinics in Developmental Medicine Nos 35-6.)

29 Chadwick O, Rutter M. Neuropsychological assessment. In: Rutter M, ed. Developmental neuropsychiatry. New York: Guilford, 1983:181-212.

30 Kandel D. Reaching the hard-to-reach: illicit drug use among high school absentees. Addictive Diseases 1975;1:465-80.

(Accepted 10 April 1989)

\title{
Inhibin: a new circulating marker of hydatidiform mole?
}

\author{
Takashi Yohkaichiya, Takao Fukaya, Hiroshi Hoshiai, Akira Yajima, David M de Kretser
}

\section{Abstract}

Objective-To define the concentrations of inhibin in serum and tissue of patients with hydatidiform mole and assess their value as a clinical marker of the condition.

Design-Prospective study of new patients with hydatidiform mole, comparison of paired observations, and case-control analysis.

Setting-A university hospital, two large public hospitals, and a private women's clinic in Japan.

Patients-Seven consecutive referred patients seen over four months with newly diagnosed complete hydatidiform mole, including one in whom the mole was accompanied by viable twin fetuses (case excluded from statistical analysis because of unique clinical features). All patients followed up for six months after evacuation of molar tissue.

End point-Correlation of serum inhibin concentrations with trophoblastic disease.

Measurements and main results-Serum concentrations of inhibin, human chorionic gonadotrophin, and follicle stimulating hormone were compared before and seven to 10 days after evacuation of the mole. Before evacuation the serum inhibin concentrations (median $8.3 \mathrm{U} / \mathrm{ml} ; 95 \%$ confidence interval 2.4 to 34.5 ) were significantly greater than in 21 normal women at the same stage of pregnancy $(2.8$ $\mathrm{U} / \mathrm{ml} ; 2 \cdot 1$ to $3 \cdot 6$ ), and inhibin in molar tissue was also present in high concentrations $(578 \mathrm{U} / \mathrm{ml}$ cytosol; 158 to 1162). Seven to 10 days after evacuation inhibin concentrations in serum samples from the same patients declined significantly to values $(0.4 \mathrm{U} / \mathrm{ml} ; 0.1$ to 1.4$)$ similar to those seen in the follicular phase of normal menstrual cycles. None of the four patients whose serum inhibin concentrations were $0.4 \mathrm{U} / \mathrm{ml}$ or less after evacuation developed persistent trophoblastic disease. Though serum human chorionic gonadotrophin concentrations declined after evacuation $\left(6.6 \times 10^{3} \mathrm{IU} / 1 ; 0.8 \times\right.$ $10^{3}$ to $\left.32.6 \times 10^{3}\right)$, they remained far higher than in non-pregnant women. Serum follicle stimulating hormone concentrations remained suppressed.

Conclusions - In this small study serum inhibin concentrations higher than those found in the early follicular phase one to two weeks after evacuation of a hydatidiform mole seemed to be specific for persistent trophoblastic disease. Further data are needed to confirm these promising results.

\section{Introduction}

Inhibin, a glycoprotein hormone produced by the testis and ovary, has the ability preferentially to suppress the secretion of follicle stimulating hormone by the pituitary. After its initial isolation from bovine follicular fluid ${ }^{1}$ we showed that inhibin was also produced by the placenta ${ }^{2}$ and that concentrations rose during early pregnancy. ${ }^{3}$ Other studies using immunocytochemistry have localised inhibin to the cytotrophoblast of the placenta, ${ }^{+}$which has been shown to contain messenger ribonucleic acid for the inhibin subunits. ${ }^{5}$ The production of inhibin by trophoblastic tissue and the availability of specific radioimmunoassays for inhibin prompted us to study the concentrations of inhibin in women with a gestational trophoblastic disease such as hydatidiform mole. This paper reports our results.

\section{Subjects and methods}

Serum and molar tissue were obtained from seven patients (median age 32 years, range 18-46) with hydatidiform mole managed at Tohoku University Hospital and its affiliated institutions. Diagnosis was based on the clinical symptoms, ultrasonic findings, laboratory data, and histological appearances of samples obtained at curettage. Gestational age at the time of primary evacuation was calculated from the date of the last menstrual period as a median of $12 \cdot 1$ weeks (range 9-17 weeks), and no patient had a previous history of gestational trophoblastic disease. All except one of the cases were diagnosed as complete hydatidiform mole without a fetus. In the exception (case 1) the hydatidiform mole coexisted with viable twin fetuses. This patient had been treated with human menopausal and human chorionic gonadotrophin for anovulation. Two months after diagnosis of the mole and despite prophylactic methotrexate one week after primary evacuation the patient had persistent trophoblastic disease. Because of the unique clinical features 


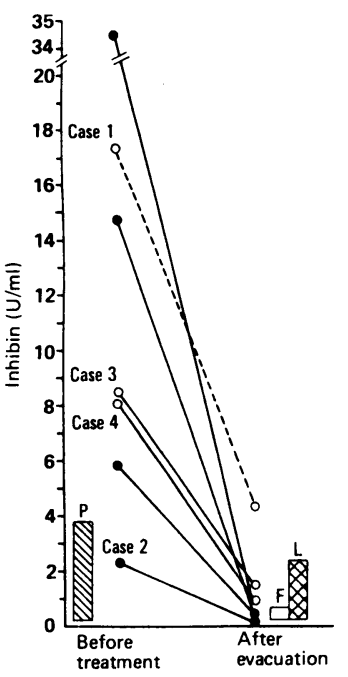

FIG 1-Serum inhibin concentrations in seven patients with hydatidiform mole before and seven to 10 days after evacuation of mole. $P, F$, and $L$ represent $95 \%$ confidence intervals of inhibin concentrations in normal pregnancy of 6-18 weeks $(P)$, early follicular phase $(F)$, and mid-luteal phase $(L)$. Confidence intervals $F$ and $L$ were calculated from data in this laboratory. ${ }^{\circ}$ Open circles represent patients who developed persistent trophoblastic disease within six months and closed circles patients who did not. Dashed line (case 1) represents data omitted from statistical analysis in text. Cases $1-4$ commented on in text

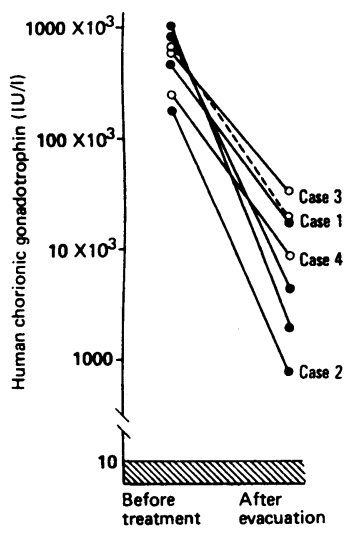

FIG 2-Concentrations of human chorionic gonadotrophin in serum of seven patients with hydatidiform mole before and seven to 10 days after evacuation of mole. Shaded area represents concentration in non-pregnant women. Symbols as in fig 1 in this case it was excluded from statistical analysis. A second patient (case 2) was also given methotrexate prophylactically, beginning two days after primary evacuation on the basis of clinical judgment about her gestational age ( 17 weeks). The other five patients were not given prophylaxis. During six months of follow up three patients (cases 1, 3, and 4) were diagnosed as having persistent trophoblastic disease and given intensive chemotherapy.

Blood samples were taken both on the day of primary evacuation and seven to 10 days thereafter. In case 2 the second sample was taken 10 days after curettage and four days after the finish of initial prophylactic chemotherapy. Molar tissue was washed extensively to remove macroscopic blood clots, homogenised without the addition of buffer, sonicated, and centrifuged at $150000 \mathrm{~g}$ for 35 minutes. Serum samples from 21 normal women with pregnancies of six to 18 weeks served as controls.

Inhibin was measured by a specific radioimmunoassay $^{67}$ using an antiserum that had been raised to inhibin fractions of increasing purity obtained during the purification of bovine $31 \mathrm{kD}$ inhibin and used with iodinated bovine $31 \mathrm{kD}$ inhibin as the tracer. The standard consisted of a pool of serum from women receiving ovarian hyperstimulation for in vitro fertilisation and which had been assayed against a previously characterised bioassay standard. ${ }^{?}$ The cross reactivity of activin $A$ transforming growth factor $\beta$, müllerian inhibiting substance, and related protein hormones was less than $0.5 \%$ in the radioimmunoassay. Concentrations of serum human chorionic gonadotrophin and follicle stimulating hormone were measured by radioimmunoassays (HCG MAIA Clone, Serono Diagnostic, Switzerland; Amerlex-M FSH radioimmunoassay kit, Amersham, United Kingdom) and used the first international reference preparation (IRP) $75 / 537$ and second IRP 78/549 as standards in each assay respectively.

Statistical analysis was by the Wilcoxon rank sum test for non-paired samples and by the Wilcoxon signed rank test for comparison of paired samples before and after treatment, and the significance of the correlation was tested by the Spearman rank correlation coefficient.

\section{Results}

Serum inhibin concentrations in six women with complete hydatidiform mole (median $8.3 \mathrm{U} / \mathrm{ml}$; $95 \%$ confidence interval 2.4 to 34.5 ) were significantly greater $(p<0.005$; Wilcoxon rank sum test) than in normal women at the same stage of pregnancy $(2 \cdot 8 \mathrm{U} /$ $\mathrm{ml} ; 2 \cdot 1$ to $3 \cdot 6)$. Seven to 10 days after evacuation of the mole concentrations declined significantly $(p<0.02$; Wilcoxon signed rank test $)$ to values $(0 \cdot 4 \mathrm{U} / \mathrm{ml} ; 0 \cdot 1$ to 1.4) similar to those seen in the follicular phase of normal menstrual cycles (fig 1). Though serum human chorionic gonadotrophin concentrations fell from a median of $527.0 \times 10^{3} \mathrm{IU} / \mathrm{l}\left(166.0 \times 10^{3}\right.$ to $\left.1018 \cdot 2 \times 10^{3}\right)$ to $6.6 \times 10^{3} \mathrm{IU} / 1\left(0.8 \times 10^{3}\right.$ to $\left.32.6 \times 10^{3}\right)$ after evacuation, they remained far higher than in non-pregnant women $(<10 \mathrm{IU} / \mathrm{l})$ (fig 2). In serum samples taken before evacuation inhibin concentrations correlated with human chorionic gonadotrophin values (Spearman rank correlation coefficient $r=0.89 ; p<0.05$ ). Though serum inhibin concentrations declined dramatically within 10 days after evacuation, serum follicle stimulating hormone concentrations were unchanged (median before evacuation $5.0 \mathrm{IU} / 1,95 \%$ confidence interval 4.0 to 5.5 ; median after evacuation $6.0 \mathrm{IU} / \mathrm{l}$, $1 \cdot 4$ to $7 \cdot 5$ ). Molar tissue contained exceptionally high concentrations of inhibin $(578 \mathrm{U} / \mathrm{ml}$ cytosol; 158 to 1162).

The patient in case 1 showed a similar pattern in all hormone concentrations studied with the exception of a high concentration of inhibin after evacuation $(4 \cdot 3 \mathrm{U} /$ $\mathrm{ml}$ ). In the other two patients who developed persistent trophoblastic disease serum inhibin concentrations after evacuation were $1.4 \mathrm{U} / \mathrm{ml}$ (case 3) and $0.9 \mathrm{U} / \mathrm{ml}$ (case 4). All four patients who remained free of persistent trophoblastic disease had serum inhibin concentrations of $0.4 \mathrm{U} / \mathrm{ml}$ or less after evacuation.

\section{Discussion}

This study shows that serum inhibin concentrations are substantially increased in patients with hydatidiform mole and may provide an important diagnostic marker of the condition. The findings are consistent with the localisation of inhibin to the cytotrophoblast of normal placenta. ${ }^{+}$

The exceptionally high concentrations of inhibin in molar tissue and the dramatic fall in concentrations in the serum after evacuation strongly support the mole as the source of the circulating inhibin. Interestingly concentrations of inhibin and human chorionic gonadotrophin were closely correlated in pretreatment serum samples. Concentrations of human chorionic gonadotrophin, however, do not have a high diagnostic value for hydatidiform mole as values in this condition show considerable overlap with those in normal pregnancy. ${ }^{89}$ On the other hand, the pre-evacuation serum inhibin concentrations in all but one patient, whose pregnancy was comparatively advanced (case 2 ), were higher than the $95 \%$ confidence interval of values in 21 normal women whose pregnancies were at a similar stage (fig 1). Further study is required to define normal inhibin concentrations in larger numbers of women in each gestational period.

Our results also suggest that serum inhibin measurements may be of value in deciding which women may be at increased risk of developing persistent trophoblastic disease, including invasive moles and choriocarcinoma. Up to now the persistence of raised human chorionic gonadotrophin concentrations after evacuation of hydatidiform mole has been used to identify patients thought to be at increased risk. ${ }^{10}$ The regression curve of serum human chorionic gonadotrophin concentrations after the evacuation of a hydatidiform mole, however, shows that it takes about 10 weeks for values to reach the non-pregnant level." Furthermore, distinguishing patients with spontaneous remission from those with persistent trophoblastic disease can be achieved only some six weeks after evacuation of the mole," so that it usually takes at least four to six weeks before chemotherapy can be started in those patients with persistent trophoblastic disease.

By contrast, the decline of serum inhibin concentrations to non-pregnant values is much more rapid, and in all our patients who did not develop persistent trophoblastic disease concentrations reached those of the early follicular phase within 10 days. Hence persistently raised inhibin concentrations one to two weeks after evacuation of a mole may provide an early indication of persistent trophoblastic disease. This is supported by the finding of postevacuation inhibin concentrations higher than those found in the early follicular phase in cases 1,3 , and 4 . These three patients showed an abnormal decline in human chorionic gonadotrophin concentrations and required chemotherapy. Our data strongly suggest that the measurement of inhibin concentrations will be of value in the management of trophoblastic disease, and we believe that further data should be collected to evaluate the concept.

We thank the staff of the department of obstetrics and gynaecology, Tohoku University Hospital; Sendai Municipal 
Hospital; Tohoku Labor Welfare Hospital; and the Imaizumi Women's Clinic for the generous supply of materials and acknowledge the technical work of Ms S Endo, Ms V McLachlan, Ms E Oliver, and Ms J Krapez. This study was supported by grants from the National Health and Medical Research Council of Australia. TY is partly supported by the Australia-Japan Foundation.

1 Robertson DM, Foulds LM, Leversha L, et al. Isolation of inhibin from bovine follicular fluid. Biochem Biophys Res Commun 1985;126:220-6.

2 McLachlan RI, Healy DL, Robertson DM, Burger HG, de Kretser DM. The human placenta: a novel source of inhibin. Biochem Biophys Res Commun 1986; 140:485-90.

3 McLachlan RI, Healy DL, Robertson DM, Burger HG, de Kretser DM. Circulating immunoactive inhibin in the luteal phase and early gestation of women undergoing ovulation induction. Fertil Steril 1987;48:1001-5.

4 Petraglia F, Sawchenko P, Lim ATW, Rivier J, Vale W. Localisation, secretion and action of inhibin in human placenta. Science 1987;237:187-9.

\section{Tissue response of gastric mucosa after ingestion of fluoride}

Department of Cariology, School of Dentistry and Departments of Surgery, Anaesthesiology, and Pathology, Karolinska Institute, Huddinge University Hospital, Huddinge, Sweden

Carl-Johan Spak, ODONTDR, associate professor in cariology Svante Siöstedt, MD, associate professor in surgery Lennart Eleborg, MD, associate professor in anaesthesiology

Béla Veress, MD, chief

consultant in morbid anatomy and histopathology

Leif Perbeck, MD, associate professor in surgery

\section{College of Dentistry,} University of Iowa, Iowa, United States

Jan Ekstrand, ODONTDR, professor in caries research

Correspondence to: $\mathrm{Dr} \mathrm{C}-\mathrm{J}$ Spak, ACO AB, Medical Department, Box 1827,

17126 Solna, Sweden.

BrMed f 1989;298:1686-7

\section{Carl-Johan Spak, Svante Sjöstedt, Lennart Eleborg, Béla Veress, Leif Perbeck, Jan Ekstrand}

Fluoride has been used successfully to prevent dental caries and has also been used to treat osteoporosis. Doses of sodium fluoride of about $50 \mathrm{mg}$ a day have long term beneficial effects on the mineral content of bone and the incidence of fracture. ${ }^{\prime}$ These doses, however, have resulted in gastric disturbances in some patients. ${ }^{12}$ We studied the response of the gastric mucosa after a single dose of fluoride.

\section{Methods and results}

Twelve healthy volunteers (age range 22-45, four men and eight women) underwent two endoscopies after overnight fasts. One endoscopy was a control and the other was performed two hours after subjects ingested $20 \mathrm{ml}$ sodium fluoride solution containing $20 \mathrm{mg}$ fluoride $(53 \mathrm{mmol} / \mathrm{l})$. There was at least two weeks between endoscopies to assure complete recovery of the mucosa in case of iatrogenic injuries from the gastroscope. During the endoscopy the mucosa was graded according to an arbitrary scale ( 0 to 4), slightly modified from that of Lanza. ${ }^{3}$ The stomach was also videotaped and the tape later examined by another gastroenterologist. The results of both exami-
Results of macroscopic and microscopic evaluations of gastric mucosa and presence of nausea at control endoscopy and endoscopy after ingestion of $20 \mathrm{mg}$ fluoride

\begin{tabular}{|c|c|c|c|c|c|c|c|c|c|}
\hline \multirow{3}{*}{$\begin{array}{l}\text { Case } \\
\text { No }\end{array}$} & \multicolumn{4}{|c|}{ Macroscopic evaluation ${ }^{\star}$} & \multicolumn{4}{|c|}{ Microscopic evaluation $\nmid$} & \multirow[b]{3}{*}{ Nausea } \\
\hline & \multicolumn{2}{|c|}{ Body of stomach } & \multicolumn{2}{|c|}{ Antrum } & \multicolumn{2}{|c|}{ Body of stomach } & \multicolumn{2}{|c|}{ Antrum } & \\
\hline & Control & Fluoride $\ddagger$ & Control & Fluoride $\neq$ & Control & Fluoride $\neq$ & Control & Fluoride $\ddagger$ & \\
\hline 1 & 1 & 4 & 0 & 4 & 0 & 2 & 0 & 2 & Present \\
\hline 2 & 0 & 4 & 0 & 2 & 0 & 2 & 0 & 2 & \\
\hline 3 & 0 & 4 & 0 & 2 & 0 & 3 & 0 & 2 & Present \\
\hline 4 & 0 & 4 & 0 & 0 & 0 & 2 & 0 & 2 & \\
\hline 5 & 0 & 4 & 0 & 1 & 0 & 2 & 0 & 1 & \\
\hline 6 & 0 & 4 & 0 & 3 & 0 & 1 & 0 & 2 & Present \\
\hline 7 & 0 & 4 & 0 & 0 & 0 & 3 & 0 & 1 & \\
\hline 8 & 0 & 3 & 0 & 0 & 0 & 1 & 0 & 0 & \\
\hline 9 & 0 & 4 & 0 & 0 & 0 & 2 & 0 & 2 & \\
\hline 10 & 0 & 4 & 2 & 0 & 0 & 1 & 0 & 2 & \\
\hline 11 & 0 & 4 & 0 & 2 & 0 & 1 & 0 & 0 & Present \\
\hline 12 & 0 & 4 & 0 & 0 & 0 & 1 & 0 & 1 & \\
\hline
\end{tabular}

Arbitrary scale: $0=$ normal, $1=$ one petechia or erosion, $2=$ two to five, $3=$ six to $10,4=>10$

tArbitrary scale: $0=$ normal, $1=$ either change in surface epithelium with oedema and haemorrhage of stroma or damage to gastric pits, $2=$ damage to both surface epithelium and gastric pits, $3=$ as 2 combined with acute inflammatory cellular response.

$\ddagger=$ Significant difference between fluoride and control according to Wilcoxon's signed rank test, $p<0 \cdot 01$.
5 Mayo KE, Cerelli GM, Spiess J, et al. Inhibin A-subunit cDNAs from porcine ovary and human placenta. Proc Natl Acad Sci USA 1986;83:5849-53.

6 McLachlan RI, Robertson DM, Healy DL, Burger HG, de Kretser DM. Circulating immunoreactive inhibin levels during the normal human menstrual cycle. J Clin Endocrinol Metab 1987;65:954-61.

7 Robertson DM, Tsonis CG, McLachlan RI, et al. Comparison of inhibin immunological and in vitro biological activities in human serum. $\mathcal{F} \mathrm{Clin}$ Endocrinol Metab 1988;67:438-43.

8 Hobson BM. Further observations on the excretion of chorionic gonadotrophin by women with hydatidiform mole. Br f Obstet Gynaecol 1958;65: 253-9.

van Leusden HA. HCG in pathologic pregnancy. Eur 7 Obstet Gynecol Reprod Biol 1973;3:137-46.

10 DuBeshter B, Berkowitz RS, Goldstein DP, Cramer DW, Berstein MR. Metastatic gestational trophoblastic disease; experience at the New England Trophoblastic Disease Center, 1965 to 1985. Obstet Gynecol 1987;69:390-5. 11 Schlaerth JB, Morrow CP, Kletzky OA, Nalick RH, D'Ablaing GA Prognostic characteristics of serum human chorionic gonadotrophin titer regression following molar pregnancy. Obstet Gynecol 1981;58:478-82.

(Accepted 24 April 1989)

imilar ( $p<0 \cdot 01$, Wilcoxon's signed ran test). Two biopsy specimens were taken from the antrum and two from the body of the stomach The histopathological changes were assessed on an arbitrary scale from 0 to 3 .

After taking fluoride all subjects had petechiae or erosions (graded 3 or 4 ) in the body of the stomach and six had changes (graded 1-4) in the antrum. No petechiae or erosions were recorded in the oesophagus or the duodenum. In four subjects a layer of clotted blood was found over a large part of the gastric mucosa The table shows the results of the macroscopic and microscopic evaluations. Three components of the gastric mucosa were affected by fluoride: the surface epithelium, the gastric pits, and the superficial stroma. The damaged epithelial cells were smaller than undamaged ones, and the vacuoles containing mucus were reduced in size or had disappeared. The most severely damaged epithelium was disrupted or totally lost. The most characteristic changes in the gastric pits were irregular dilatation and flattening of the epithelial cells. There was also a noticeable loss of mucin.

\section{Comment}

Our study showed that one ingestion of fluoride at a dose used to treat osteoporosis affects the gastric mucosa. We do not know, however, to what extent repeated doses affect the mucosa, which might adapt after a while, as occurs with regular treatment with aspirin. ${ }^{3}$ Our findings confirm data from experiments on animals, which showed that fairly low concentrations of fluoride can damage the surface of the gastric mucosa. ${ }^{4}$

The low $\mathrm{pH}$ of gastric juice and the formation of hydrogen fluoride probably caused the mucosal injuries. The uncharged molecule can easily penetrate the lipid cell membranes, enter the cell, and dissociate to fluoride and hydrogen ions, which may have toxic effects on enzyme systems and cause structural damage.

Symptoms like nausea and vomiting are not unusual when fluoride is used to treat osteoporosis. ${ }^{2}$ They also occur occasionally when high doses are used for dental prophylaxis. ${ }^{5}$ In our study only four subjects developed nausea, which suggests that using nausea as the first sign of fluoride toxicity might not be valid as all our subjects showed mucosal damage.

Finally, our results are also clinically important in dentistry because as much as 30 mg fluoride may be swallowed by children after prophylactic treatment with fluoride gel ( $1.23 \%$ fluoride). ${ }^{5}$ If the risk of subsequent gastric injury is as high as our results suggest the use of such large amounts of fluoride in children should be questioned.

Part of this study was supported by grants from the Swedish Medical Research Council (No 6002) and the 